\title{
A Contribuição do Caráter "Transversal" do Software para a Política de Inovação
}

\section{Emerson Freire}

Doutorando do Departamento de Política Científica e Tecnológica - Instituto de Geociências - UNICAMP Sandra de Negraes Brisolla

Professora do Departamento de Política Científica e Tecnológica - Instituto de Geociências - UNICAMP

Recebido: 9/4/2003 Aprovado: 3/6/2004

\section{RESUMO}

Não resta dúvida de que uma das grandes dificuldades do processo inovativo das empresas brasileiras de software está, pelo menos por enquanto, na pouca capacidade de articulação de umas com as outras, bem como com os centros de pesquisa e desenvolvimento tecnológico, e com os diversos setores para os quais teria a possibilidade de realizar seus projetos informacionais. Trata-se aqui de ilustrar a atuação de um segmento dessa indústria no setor da construção, historicamente avesso à inovação, comprovando que as TIs (Tecnologias da Informação) difundem-se mesmo através de setores tradicionais, servindo não só como suporte administrativo mas, também, como ferramentas estratégias nas empresas. Mais ainda e, principalmente, o estudo pretende exemplificar que características típicas do software são válidas inclusive para setores tradicionais e com processos praticamente "artesanais", e que influenciam na competitividade do setor tanto nacional como internacionalmente. Entre essas características do setor de software destaca-se seu caráter transversal e sua importância na política de inovação junto aos outros setores da economia.

\footnotetext{
* Os autores agradecem aos pareceristas anônimos que revisaram este texto pela leitura atenta e comentários precisos que foram incorporados e permitiram aprimorar o trabalho.
} 
Palavras-Chave | Indústria de Software; Tecnologias da Informação; Política de Inovação; Transversalidade; Indústria da Construção

Códigos JEL | L86; O38; L74

\section{ABSTRACT}

There is no doubt that one of the great difficulties of the innovative process in Brazilian software companies is, at least for the time being, their little articulation ability with each other, as well as with research and technological development centers and with the several sectors for which it would have the possibility to accomplish its informational projects. Here, it will be analyzed a software segment applied to the construction industry, historically averse to the innovation, proving that ITs (Information Technologies) are diffusing thoroughly even in traditional sectors, serving not only as administrative support but also as a strategic tool in the companies. Moreover, and, mainly, the study intends to exemplify that typical characteristics of the software are valid even for traditional sectors with almost "craft" processes, and influence the sector competitiveness both national and internationally. Among those software sector characteristics it emphasizes its "transverse" character and its importance in the innovation policies regarding to the other economic sectors.

KeYwORDS I Software Industry; Informational Technologies; Innovation Policies; Transverse; Construction Industry

JEL-CODES | L86; O38; L74 


\section{O setor de software e as abordagens de Sistemas de Inovação}

Desde Schumpeter que a inovação tecnológica não é mais concebida como variável exógena ao sistema econômico. Agora, mais do que nunca, é necessário atribuir-lhe o verdadeiro valor, incluindo-a em uma perspectiva mais abrangente, o Sistema de Inovação (SI).

Ao analisar as estratégias contemporâneas dos países centrais, enfatizando a criação de competitividade via esforços de pesquisa e também na aplicação e difusão de resultados, J.J. Salomon (citado em Sutz, 1996:99) afirma: "Esta é a mudança mais importante e reveladora: a política de inovação aparece como uma extensão (ou uma alternativa) ao que antes se chamava política de ciência e tecnologia."

Três elementos estão no centro da nova conceitualização sobre a inovação (Sutz, 1996), todos importantes para definir orientaçôes e sugerir propósitos aos estudos em contextos subdesenvolvidos, mesmo não sendo aí que tenham sido criados:

a) assinala-se que a inovação não é um processo concentrado em algum lugar privilegiado do corpo social, por exemplo, as grandes empresas, ou aquelas que produzem bens de capital. Ao contrário, a inovação é um processo socialmente distribuído, no qual intervêm múltiplos atores e onde os usuários ocupam lugar relevante em matéria de orientação das mudanças;

b) caracteriza-se a inovação como um processo interativo, sendo que a relação usuário-produtor é a melhor garantia, tanto para que a inovação chegue a produzir-se, como para que esta maximize sua utilidade social;

c) indica-se que um contexto privilegiado, no qual se produzem as inovações, é o nacional (Lundvall, 1992), o que levou a estabelecer outro conceito central: o Sistema Nacional de Inovação (SNI).

Vários autores, com o objetivo de propor o conceito de SNIs, argumentam que desempenhos nacionais, referindo-se à inovação, provêm de uma convergência social e institucional particulares e de características histórico-culturais. Sendo assim, deve-se destacar que o conceito de SNI foi criado para contrapor-se à idéia de que a globalização teria varrido as fronteiras nacionais do mapa. 
O conceito recupera a importância do papel do Estado e das culturas nacionais no processo de inovação.

Smith (1997) argumenta, assim como alguns outros autores, que os diferentes enfoques de SNIs estruturam-se em três pilares básicos, que permitem distingui-los e diferenciá-los de acordo com a ênfase colocada em cada um deles. Tais pilares baseiam-se no entendimento de que:

a) as vantagens competitivas resultam da variedade e da especialização, e tal fato realmente apresenta efeitos indutores path-dependents. ' Isto é, especializações que apresentam sucesso econômico - com criação de sistemas como resultado - ocorrem particularmente ao redor de estruturas industriais específicas;

b) o conhecimento tecnológico é gerado por intermédio de um aprendizado fundamentalmente interativo, tomando, em geral, a forma de capacitações distribuídas entre os diferentes agentes econômicos que devem se relacionar de alguma maneira, para que o mesmo possa ser utilizado;

c) o comportamento econômico repousa em instituiçôes e "regras do jogo" estabelecidas legalmente ou por meio de costumes que evoluem, tendo em vista as vantagens que elas oferecem na redução da incerteza. Assim, diferentes modos de organização institucional levam a diferentes comportamentos e resultados econômicos.

Dessas considerações, deduz-se que as capacidades de inovação e aprendizagem encontram-se intimamente atreladas às estruturas social, institucional e produtiva de cada nação/região, sendo que a história é considerada, logicamente, como uma fonte importante de tal diversidade.

A literatura sobre os SNIs ou, mais recentemente, sobre os diversos sistemas de inovação, ainda não indica como caracterizá-los definitivamente. De qualquer forma, López e Lugones (1999) em uma taxonomia dos sistemas de inovação, dentro de uma perspectiva geográfica, citam diversas instâncias desses sistemas, a partir das contribuições de autores como Lundvall (1992), Nelson (1993), Edquist (1997), entre outros:

\footnotetext{
Path-dependents designa o efeito através do qual uma opção tecnológica (ou de especialização) determina as inovações seguintes, que passam a ser dependentes do caminho escolhido.
} 
a) Sistemas Regionais de Inovação (SRI). Esse conceito remonta à tradição de estudos de experiências bem-sucedidas de desenvolvimento "local”, cujos exemplos mais "célebres" são as áreas high-tech do Silicon Valley e da Route 128 nos Estados Unidos, ou a zona de Cambrigde na Grã-Bretanha, enquanto os "distritos industriais" italianos exemplificam casos de desenvolvimento baseados, geralmente, em indústrias "tradicionais" (têxteis, cerâmicas, etc.); ${ }^{2}$

b) Sistemas Setoriais de Inovação (SSI). Define-se como uma rede de agentes que interagem em uma área tecnológica específica, sob uma infra-estrutura institucional determinada, com o propósito de gerar, difundir e utilizar tecnologias;

c) Sistemas Supranacionais de Inovação (SSNI). Os autores citam como exemplo a União Européia (UE), como provável e desejado caminho para o Mercosul.

Os estudos que vêm sendo realizados sobre SNI, SRI, SSI e SSNI, conformam um "quadro conceitual", sugerindo algumas idéias e argumentos em torno da questão. Os fundamentos que enfatizam os aspectos regionais e locais (diversidade) são: o aprendizado; as interações; as competências; as complementaridades; a seleção; a característica de path-dependents (Cassiolato \& Lastres, 1999).

De forma particular, os limites nacionais servem para identificar os atores que compartilham uma cultura, história, linguagens e instituições sociais e políticas comuns, e que estão imersas em estruturas produtivas específicas. Estes atores devem ser considerados em todos os subsistemas.

É por isso que quando se quer ilustrar o problema da caracterização dos SNIs através de uma analogia, não se deve escolher a de um mosaico, já que suas peças são funcionalmente idênticas. Corresponderia, sim, pensar em uma casa, que se constrói com muitos elementos diversos, cada um deles desempenhando uma função específica (Sutz, 1999).

Entre os elementos que se consideram determinantes da conformação desse cenário, destaca-se o conjunto de novas tecnologias informacionais e de comunicações, que são decisivas na configuração de uma nova geografia, encur-

\footnotetext{
2 Na literatura, incluindo López \& Lugones (1999), sobre os SRI (principalmente quando se trata dos conglomerados marshallianos, em sua versão moderna chamados "distritos industriais"), os tais exemplos bem-sucedidos resumem-se aos países centrais ou, quando muito, referem-se ao Leste Asiático.
} 
tando as distâncias e possibilitando a comunicação imediata - em tempo real entre agentes econômicos nos mais longínquos pontos do planeta.

Aplicados à atividade industrial, transformando radicalmente as formas de produzir, os programas informacionais alteram o mecanismo da formação de valor na sociedade capitalista, progressivamente despojado de seu conteúdo material, para incluir crescentes quantidades de trabalho potenciado, "valorizado" por sua capacitação.

É neste sentido que a abordagem dos SSI torna-se apropriada à análise da indústria de software. Essa abordagem avança no sentido de fornecer uma visão multidimensional, integrada e dinâmica dos setores, tal como se faz necessário para o estudo de uma indústria com as características da indústria de software. Os agentes, dentro da visão dos SSI, são indivíduos e organizações com vários níveis de agregação, com específicos processos de aprendizado, competências, estrutura organizacional, crenças, objetivos e comportamentos. Eles interagem através de processos de comunicação, troca, cooperação, competição, e suas interaçõos são delineadas pelas instituições (Malerba, 2001).

Os motivos da criação de software e o propósito para os quais são criados diferem entre os atores que estão envolvidos nessa indústria. Neste sentido, uma boa alternativa para analisar as interações entre os atores é vê-los conjuntamente em um SSI (Malerba, 1999; Edquist, 1997).

A abordagem dos SSIs é complementar aos demais conceitos sobre sistemas de inovação, tais como o SNI e o SRI, adicionando valor pela sua ênfase em trabalhar melhor o papel dos relacionamentos sistêmicos no fluxo de conhecimentos concernentes à inovação. Particularmente, as inovaçôes de produto são provavelmente beneficiadas pelo fortalecimento do relacionamento usuário-produtor, pelo aprimoramento da capacidade das instituições públicas de pesquisa, incluindo as universidades, para uma real interação com a indústria, e pela emergência de uma efetiva cooperação interfirma ou de "rede" dentro de uma indústria.

Infelizmente, esses mecanismos não operam com o devido grau de confiança ou estabilidade na indústria de software, pois suas contribuições são episódicas ou transitórias. Isso sugeriria que esta indústria é um sistema setorial de inovação incoerente, porém, na verdade, sua estrutura sendo bem delineada, trará uma significativa reorganização da divisão do trabalho inovativo na produção de software (Steinmueller, 2001). 
Neste sentido, a partir da idéia dos SSI e lembrando que a divisão de trabalho na indústria de software dá-se de forma hierarquizada, setorial e internacionalmente, a produção de software torna-se fundamental para que um país possa estimular a competitividade de suas empresas e construir uma capacitação tecnológica com o desenvolvimento de sistemas de informação adequados às necessidades das empresas locais.

No paradigma técnico-econômico atual, a inovação e o conhecimento necessários para a sua geração e difusão são elementos centrais da dinâmica e do crescimento de nações, regiôes, setores e empresas. A inovação constitui-se em processo relacionado ao aprendizado, dependente de interaçoes, socialmente determinado e fortemente influenciado por formas institucionais e organizacionais. Grande parte, se não o total do conhecimento necessário para desenvolver produtos genéricos, como é o caso dos softwares-pacote globais, surge de experiências localizadas e especializadas, sendo que os passos inovativos requeridos envolvem a capacidade de criar generalizações conceituais dessas experiências.

Basicamente, o desenvolvimento de uma indústria de software local, visando tanto o mercado interno quanto o externo, pode impulsionar o desenvolvimento regional por dois motivos principais. Em primeiro lugar, o software é um produto facilitador de interações. Desta forma, empresas de software locais podem contribuir com soluçôes específicas para redes de empresas localizadas na região e, portanto, estimular a capacidade inovadora e a competitividade destas redes. Em segundo lugar, o desenvolvimento de uma indústria de software requer a construção de competências que podem gerar sinergias para o desenvolvimento de outras atividades de alta tecnologia.

Ademais, com a crescente internacionalização das atividades produtivas, $\mathrm{o}$ software configura-se cada vez mais, através daquilo que se pode chamar de seu "caráter transversal", como parte integrante das diferentes cadeias, sendo nestas um "elo" não só relevante como praticamente obrigatório.

É difícil imaginar hoje, em segmentos como o de telecomunicações, o software como um agente dissociado do processo total. Por exemplo, parte significativa do valor das centrais telefônicas está associada ao software embarcado, ${ }^{3}$ ou

\footnotetext{
3 Tipo de software que tem como característica chegar ao mercado embutido em um equipamento. Atualmente, a maioria dos equipamentos automatizados traz consigo um software - mesmo que simplificado - para operacionalizá-lo, o que torna a atividade de desenvolvimento desse tipo de software uma das mais importantes e dinâmicas.
} 
seja, o software representa parte essencial da atividade como um todo. Mesmo em outros segmentos, como na indústria eletroeletrônica, a importância do software vem crescendo de forma relevante nos últimos anos.

$\mathrm{Na}$ automação industrial, o software - que surgiu inicialmente embarcado em funções simples - também vem ganhando importância com o aumento da complexidade das funções programáveis do equipamento, ou seja, o software torna-se um determinante da flexibilidade dos equipamentos automatizados e dos processos robotizados, bem como de sua integração ao processo de produção.

Além desse tipo de software, básico e de produtividade, um outro tipo deve ser considerado, o software profissional ou de gestão. Este software é desenvolvido visando um determinado segmento econômico, ou até mesmo vários, incorporando funções específicas às diversas atividades, automatizando e integrando processos. No caso da automação bancária, ou ainda de empresas prestadoras de serviços públicos, que necessitam trabalhar uma grande quantidade de informações em "tempo real", esse tipo de software é muito importante.

No Brasil, com a abertura do mercado na década passada, as empresas nacionais viram-se obrigadas a aumentar a competitividade e se modernizar para não perder o market share ${ }^{4}$ para as estrangeiras ou até mesmo ir à falência. Neste contexto, o uso crescente de tecnologia da informação, em especial de software, tornou-se um pré-requisito básico para poder competir e se manter em um mercado cada vez mais globalizado.

O setor industrial brasileiro, por exemplo, foi a atividade econômica que mais precisou se modernizar para poder continuar competindo após a abertura do mercado, e para não ser "engolido" pelas empresas estrangeiras que passaram a atuar no Brasil nesta última década. O mesmo ocorreu no setor comercial, que introduziu maciçamente softwares de gerenciamento de suas atividades.

Desse modo, o uso de tecnologia da informação para impulsionar os negócios se tornou imprescindível para as empresas nacionais sobreviverem e, com isso, as software-houses ${ }^{5}$ brasileiras se viram face a uma demanda crescente para atender às necessidades da indústria de automatizar processos, reduzir custos e

\footnotetext{
4 Parte de sua participação no mercado, sua fatia de mercado.

5 Termo comum utilizado para os fabricantes de software, empresas que desenvolvem e vendem programas de computador.
} 
aumentar a eficiência e a produtividade. Isso ocorreu em menor medida também no comércio e nos serviços, ainda que o desafio para as software-houses nesses casos fosse menor.

Os estabelecimentos industriais existentes no País estão utilizando tecnologia cada vez mais avançada em seus processos produtivos e de gerenciamento, mas ainda há uma demanda considerável a ser explorada, uma vez que o número de empresas que inovam, no Brasil, ainda é baixo se comparado ao desempenho dos países centrais, ou até mesmo em relação a outros países em desenvolvimento. Desta forma, o setor industrial ainda constitui uma boa área de atuação para as software-houses brasileiras.

Esses aspectos discutidos anteriormente justificam uma análise da atuação da indústria de software sobre outras áreas econômicas, avaliando sua dinâmica, composição e seus resultados. A valorização da diversidade oferece ganhos de competitividade à indústria nacional na medida em que aumentam as chances de serem implementadas em estratégias variadas de concorrência em um mercado caracterizado por um elevado grau de segmentação, como é o caso do software. As vantagens competitivas adquiridas necessitam, por sua vez, de uma busca contínua de renovação através de um processo de aprendizagem intermitente.

A "transversalidade" do software em muitos setores é fácil de ser visualizada, tornando-se motivo de estudos constantes em setores como telecomunicações, eletroeletrônico, bancário e comercial. A proposta deste texto é, por outro lado, demonstrar a importância de se desenvolver a indústria de software para benefício até mesmo de setores que estão muito aquém da classificação como hightech, tradicionalmente pouco inovativos, mas que vêm sentindo os ventos das mudanças no seu dia-a-dia e tendo que se adaptar a eles, como é o caso da indústria da construção.

A intenção é enfatizar o caráter "transversal" do software, verificando os desafios particulares para essa indústria em sua atuação na construção e salientando sua importância para sanar um dos problemas que esta última enfrenta há tempos, ou seja, o da integração das chamadas "ilhas de automação na construção", isto é, a integração entre arquitetura, engenharia e construção propriamente dita, tudo isso dentro de uma visão global da empresa.

Obviamente, a "transversalidade" do software neste ramo de atividade não tem ainda caráter tão explícito quanto aquele assinalado anteriormente para 
outros setores; no entanto, a tendência no setor da construção é cada vez maior no sentido de enfatizar o software como elemento necessário, como já de fato acontece no design do produto.

Uma das propostas que surgiu com muita força a partir dos anos noventa foi a solução denominada SGI - Software de Gestão Integrada ou ainda SIS Soluções Integradas em Software, em especial os sistemas do tipo ERP - EntERPrise Resource Planning, verdadeira febre na década passada. Claro que, neste caso, esta afirmação não se refere somente à indústria da construção, muito pelo contrário. Esse tipo de software entrou de forma mais lenta no setor, primeiramente, e principalmente através das grandes empresas, sendo depois seguido pelas médias, porém em um segmento médio (midrange) dessas tecnologias de gestão empresarial.

A seguir, então, faz-se primeiro uma descrição deste tipo de software e depois se entra na análise do software na indústria da construção propriamente dita, dando ênfase às soluçōes integradas.

\section{Software de Gestão Integrada (SGI)}

No final dos anos 1990, as tendências em TI na indústria brasileira apontaram para a maior utilização de redes de informação, o aumento expressivo no uso dos MES - Manufacturing Execution Systems e dos sistemas de ERP, o uso de computação móvel, o maior controle do chão-de-fábrica, e o uso dos sistemas de CRM - Customer Relationship Management.

$\mathrm{O}$ crescimento das redes intra e interfirmas estimulou as organizações a desenvolverem novas linguagens, padróes e interfaces. Sendo assim, esses tipos de software (SGI) passaram a ser usados em grande escala, destacadamente o software ERP, como alternativa aos sistemas de softwares que eram comumente construídos internamente pelas grandes empresas.

Originalmente aplicado a empresas de manufatura, o uso dos sistemas ERP vem se difundindo por todos os tipos de negócios, incluindo o comércio varejista, empresas públicas e organizações prestadoras de serviço de saúde.

O ERP nada mais é do que um programa (software) que tem por objetivo integrar em uma única base de dados todas as informaçôes e aplicativos (programas modulares) dos diversos departamentos e funçôes de uma organização - 
áreas contábil, financeira, controladoria, gerenciamento dos investimentos, planejamento da produção, controle de materiais, custos, vendas, distribuição, marketing, gerenciamento da qualidade, recursos humanos, gerenciamento de informação e demais funçôes existentes em uma empresa produtora de bens ou em uma organização prestadora de serviço - buscando sua integração para satisfazer prontamente as necessidades de obtenção de dados e informações de todas as partes da organização.

Davenport (1998:124) apresenta resumidamente as funcionalidades dos sistemas ERP separando-as em funções de back-office, compostas por recursos humanos, manufatura e finanças, front-office, compostas por vendas e serviços, além da tecnologia e do chamado supply-chain management ou administração da cadeia de suprimentos. Este modelo pode ser visto na Figura 1.

Na verdade, o ERP é uma tecnologia que se destina a adequar as organizações ao novo paradigma técnico-produtivo baseado na informação e à nova

FIGURA 1

Funcionalidades de um sistema ERP

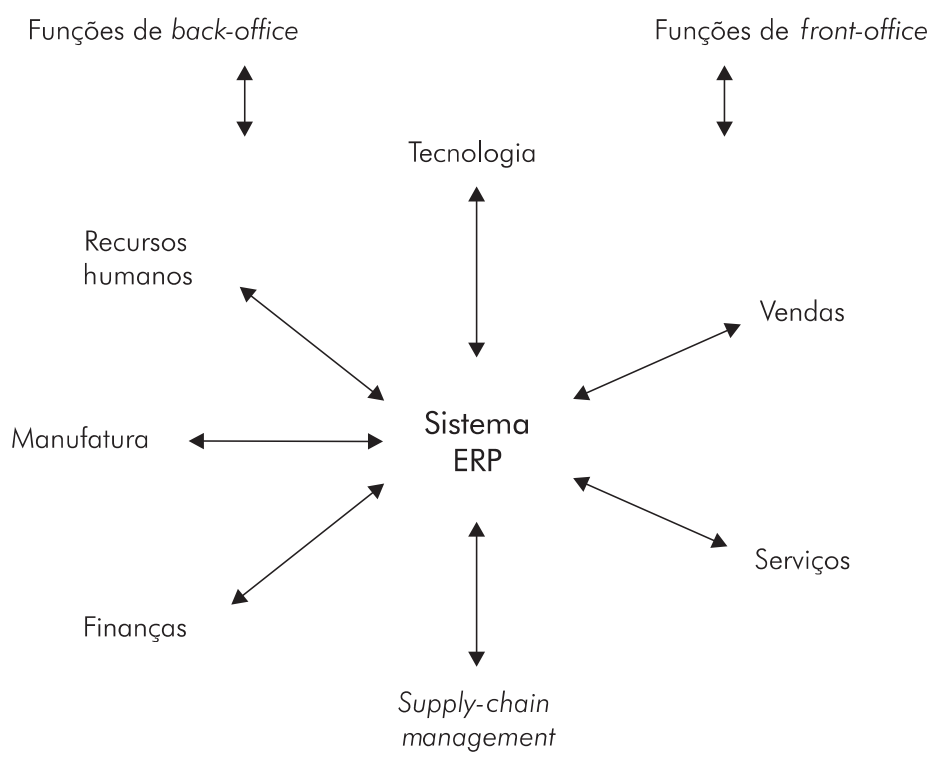

Fonte: Davenport (1998:124) 
realidade concorrencial das economias e mercados globalizados, em busca de patamares mais elevados de produção, produtividade e competitividade. Possibilita a otimização de processos produtivos, a diversificação na oferta de produtos, a redução de erros e falhas, a agilização na tomada de decisões e a interação flexível com o mercado, clientes e fornecedores.

Claro que essa aparente fórmula de sucesso em forma de pacote tecnológico tem seus custos, que não são pequenos, principalmente os financeiros. $\mathrm{O}$ preço de aquisição desses softwares geralmente é muito alto, além de interferir na estrutura da empresa como um todo. Adquirir ou não este tipo de programa passa a fazer parte do comportamento estratégico da empresa, a maioria das vezes visando redução de custos de produção e trabalhistas.

Dentre os impactos mais importantes da implementação desse software estão a transformação dos métodos e processos de trabalho tradicionais, a reformulação dos perfis profissionais e das ocupações funcionais, redefinindose os pré-requisitos de formação educacional e também as exigências de treinamento e de desenvolvimento de competências, e a reestruturação organizacional, como decorrência direta do processo de integração e verticalização, incluindo o redesenho da estrutura organizacional, muitas vezes promovendo a redução dos níveis hierárquicos e a concentração das instâncias decisórias e executivas.

Esses produtos de soluções integradas costumam ser genéricos, no sentido de serem destinados a atender uma comunidade de usuários relativamente grande, mas, por outro lado, eles são também "localizados", isto é, suas aplicações exigem uma quantidade substancial de especificações de usuários e customização, geralmente atingidas com a ajuda de vendedores e consultores externos. Por conseqüência, a maioria dos SGI exige cada vez mais um trabalho conjunto e eficaz de pós-venda, o que implica demandas para o setor de software serviço ou customizado, tais como: análise detalhada para a integração, e os esforços de customização necessários para adequar o pacote ERP à organização usuária.

Desse modo, obtém-se um tipo de software híbrido, vendido em forma de pacotes, porém com necessidade de customização, tornando até mesmo a tarefa de uma classificação strictu senso dos sistemas ERP relativamente complicada. Existe, então, uma divisão de trabalho entre os desenvolvedores de sistemas integrados e os fornecedores especializados na customização, que é alavancada por uma crescente padronização e codificação das ferramentas de desenvolvimento de software, mé- 
todos e procedimentos, bem como uma também crescente padronização da arquitetura de produto, isto é, das plataformas e interfaces utilizadas (D’Adderio, 2000).

De qualquer forma, o interessante a observar é que as interações usuáriodesenvolvedor estão mudando de uma colaboração no desenvolvimento do projeto para uma intermediação ativa no processo, através de grupos focados no desenvolvimento, grupos de usuários, relatórios de defeitos no produto, de exposições e do uso de versões beta. Além disso, há uma maior dependência de consultoria e de firmas de integração, para suprir os requisitos da base de conhecimento em tecnologia da informação necessários à implantação e sustentação desses sistemas ERP. Sem dúvida, essa estruturação exige uma infra-estrutura para a codificação e circulação do conhecimento "tácito" entre as diferentes divisões e funções, no desenvolvimento e implementação do software. ${ }^{6}$

Em software, o conhecimento sobre o contexto da aplicação é fundamental. Portanto, as interações usuário-produtor desempenham papel crucial no processo de inovação, ${ }^{7}$ sendo que, de fato, a proximidade dos usuários se torna essencial para o desenvolvimento do software. Em outras palavras, a inovação tem uma natureza sistêmica e está freqüentemente relacionada ao design. Desse modo, na visão de um sistema setorial de inovação para uma indústria com caráter "transversal" cada vez mais visível como a do software, produção e difusão de software não devem ser mais analisadas como tópicos distintos, pois se misturam e se revezam constantemente em importância para a alimentação do processo inovativo. Certamente, os sistemas de solução integrada comprovam essa afirmação, principalmente se for observada a atuação das empresas líderes no segmento de ERP.

Dentro do mercado de software, sem dúvida, os softwares-pacote adquiriram crescente importância se comparados ao software por encomenda. Por exemplo, em 1991, a demanda nos Estados Unidos por software era de $40 \%$ do mercado mundial e as empresas estadunidenses tinham $87 \%$ do mercado mundial de software-pacote; as empresas européias, por sua vez, contavam com 16\% da produção mundial e eram responsáveis por $11 \%$ do consumo de softwarepacote (Malerba \& Torrisi 1996).

6 Para mais detalhes sobre o conhecimento tácito e codificado na produção de software e suas implicações na divisão de trabalho entre firmas, consultar Grimaldi \& Torrisi (2001).

7 A importância da interação usuário-produtor pode ser vista mais detalhadamente na análise de Cassiolato (1992) sobre o processo de automação bancária no Brasil. 
Desde então, o mercado de software-pacote continuou sendo dominado por empresas dos Estados Unidos, enquanto as empresas européias se especializaram, principalmente, em serviços e concentraram-se em mercados relativamente pequenos. Ainda segundo Malerba e Torrisi (1996), muitas vezes faltou ao mercado europeu oportunidade para economias de escala e de escopo, as quais são essenciais para sustentar a competitividade na área de softwarepacote, devido à sua fragmentação, o que é atribuído a uma série de diferenças históricas, culturais, lingüísticas, legais e fiscais.

No entanto, embora estas hipóteses expliquem a tendência predominante, a atuação de grandes empresas européias no segmento de ERP, com estratégias globais, indica que as características estruturais do mercado isoladamente não são suficientes para determinar os resultados competitivos. Exemplos de sistemas ERP existentes no mercado são o R/3 da alemã SAP, o OneWorld da estadunidense JD Edwards, o Oracle Applications da também estadunidense Oracle, o AP7 da brasileira Microsiga e o EMS da brasileira Datasul.

Os serviços de integração, que geralmente incluem infra-estrutura (banco de dados, redes corporativas, servidores, etc.), aplicativos (ERP high-end e midrange, CRM, Supply Chain, etc.) e mercados verticais (finanças, telecomunicações, governo, engenharia, comércio, etc.), atingiram as cifras entre 2002 e 2003, de U\$ 900 milhóes para U\$ 1,1 bilhão, respectivamente, o que representaria 30,6\% dos serviços profissionais de informática, segundo a revista Os 100 Maiores Integradores 2004.

A Tabela 1 traz um ranking recente das empresas que atuam no Brasil no segmento ERP high-end. A categoria high-end atende a uma demanda de empresas de grande porte, geralmente com faturamento acima de US\$300 milhôes anuais, o que lhe proporciona um universo relativamente pequeno de empresas.

$\mathrm{Na}$ categoria midrange, uma grande parcela dos clientes apresenta faturamento anual entre US\$100 e 150 milhões, sendo que a brasileira Microsiga é a líder local. Segundo os dados de Os 100 Maiores Integradores 2004 (Tabela 2), a Microsiga representa aproximadamente 29\% do mercado nacional, percentual que pode ser considerado elevado, dado que se trata de uma empresa nacional atuando em um mercado altamente oligopolizado internacionalmente. 
TABELA 1

As maiores em receita no segmento ERP - High-end no Brasil (2003/2002)

\begin{tabular}{lccc}
\hline Empresa & $\begin{array}{c}\text { Receitas no segmento 2003 } \\
\text { (US \$ 1.000) }\end{array}$ & $\begin{array}{c}\text { Receitas no segmento 2002 } \\
\text { (US\$ 1.000) }\end{array}$ & $\begin{array}{c}\text { Participação de mercado } \\
(\%)\end{array}$ \\
\hline Accenture & 30.054 & 24.489 & $24,6 \%$ \\
Atos Origin & 15.767 & 9.978 & $12,9 \%$ \\
Stefanini & 8.021 & 7.109 & $6,6 \%$ \\
Softtek & 7.202 & 7.106 & $5,9 \%$ \\
SAP & 5.951 & 5.824 & $4,9 \%$ \\
IBM & 5.444 & 2.000 & $4,4 \%$ \\
DBA Engenharia & 4.920 & 4.295 & $4,0 \%$ \\
InfoJBS & 4.369 & 4.108 & $3,6 \%$ \\
Gennari \& Peartree & 4.211 & 3.409 & $3,4 \%$ \\
UniOne & 3.961 & 3.537 & $3,2 \%$ \\
Outros & 32.491 & 26.917 & $26,5 \%$ \\
Total & 122.391 & 98.772 & $100,0 \%$ \\
\hline
\end{tabular}

Fonte: elaboração própria a partir de Os 100 Maiores Integradores - 2004.

Obs: valores do dólar médio $=R \$ 3,11678$ e $R \$ 2,96705$, para 2003 e 2002, respectivamente.

O interessante a se observar no caso da empresa Microsiga é que um dos fatores diferenciais mais importantes para sua competitividade neste segmento é justamente sua origem nacional, com franquias em vários estados, trazendo facilidades de adaptação de seus produtos tanto em relação à legislação do País quanto no que se refere às diferenças regionais.

As soluções ERP para pequenas e médias empresas, com faturamento abaixo de US\$ 100 milhões, incluem-se na categoria low-end. Nesta, os principais fatores de competitividade são preços e prazos de implantação. Se, por um lado, um contrato de fechamento ERP high-end leva, em alguns casos, seis meses e a implantação um prazo superior a um ano (segundo a complexidade), por outro, o fechamento de um contrato low-end costuma não demorar mais do que 45 dias. A Microsiga também é a empresa líder no segmento low-end 
TABELA 2

As maiores em receita no segmento de gestão integrada midrange no Brasil (1998)

\begin{tabular}{lccc}
\hline $\begin{array}{l}\text { Empresa } \\
\text { Microsiga }\end{array}$ & $\begin{array}{c}\text { Receitas no segmento 2003 } \\
\text { (US 1.000) }\end{array}$ & $\begin{array}{c}\text { Receitas no segmento 2002 } \\
\text { (US \$1.000) }\end{array}$ & $\begin{array}{c}\text { Participação de mercado } \\
(\%)\end{array}$ \\
Datasul & 34.898 & 33.256 & $52,0 \%$ \\
RM Sistemas & 7.946 & 8.493 & $12,0 \%$ \\
InfoJBS & 4.373 & 2.524 & $7,0 \%$ \\
Stefanini & 2.410 & 1.930 & $4,0 \%$ \\
Atos Origin & 1.989 & 1.719 & $3,0 \%$ \\
Gedas & 1.806 & 1.143 & $3,0 \%$ \\
UniOne & 1.471 & 1.159 & $2,0 \%$ \\
Itautec & 1.411 & 1.603 & $2,0 \%$ \\
Unitech & 1.001 & 1.083 & $2,0 \%$ \\
Outros & 930 & 782 & $1,0 \%$ \\
Total & 8.330 & 7.116 & $12,0 \%$ \\
& 66.565 & 60.808 & $100,0 \%$ \\
\hline
\end{tabular}

Fonte: elaboração própria a partir de Os 100 Maiores Integradores - 2004.

Obs: valores do dólar médio $=R \$ 3,11678$ e $R \$ 2,96705$, para 2003 e 2002, respectivamente

brasileiro, com um market share de 43\%. Ela tem uma estratégia diferenciada da empresa SAP, por exemplo. Enquanto esta última procura comercializar versões reduzidas (compactas) do sistema $\mathrm{R} / 3$, retirando módulos (ou funções) e tornando-se compatível com os segmentos de mercado de SGI não dominados pela empresa (midrange e low-end), a primeira procura conquistar mercado através da incorporação das necessidades de cada cliente ao software básico da empresa.

\section{A transversalidade do software: o caso da construção}

Para os profissionais da construção, o surgimento do entusiasmo inicial pelas aplicações computacionais dá-se no começo dos anos 1960. Havia um olhar otimista diante do potencial dos computadores como ferramenta de 
auxílio no design e na própria edificação, e quanto ao tempo necessário para se desenvolver esse potencial. Nos anos 1970 e começo dos 1980, a excitação inicial foi substituída por um maior realismo sobre o que os computadores poderiam oferecer (Bazjanac, 1975). Essa mudança de opinião ocorreu em decorrência da combinação entre os altos custos de capital do hardware e as limitações dos softwares naquela época. A partir de meados dos anos 1980, a penetração dos computadores na indústria da construção tem-se acelerado graças ao rápido desenvolvimento do hardware, essencialmente dos computadores pessoais (PCs) e, conseqüentemente, do desenvolvimento de softwares aplicativos.

Desde então, há uma consciência cada vez maior das necessidades de mudança dentro da indústria da construção, o que é resultado principalmente:

a) do potencial existente para o decréscimo dos custos de construção através da padronização dos processos de construção;

b) do aumento da demanda e sofisticação dos clientes;

c) das exigências crescentes em relação à funcionalidade do projeto pelo aumento da competição;

d) do rápido desenvolvimento nas tecnologias da informação;

e) da entrada de novos materiais - geralmente importados - que exigem a transformação das formas de produção.

No entanto, existem alguns fatores que impedem a indústria da construção de alcançar melhoras significativas como as já atingidas por outras indústrias de manufaturas e serviços:

a) cadeia de fornecedores fragmentada. A indústria da construção compõe-se de uma grande quantidade de empresas, em sua maioria de pequeno e médio porte. A maior parte dos projetos de construção é executada em parceria, freqüentemente envolvendo um grupo de 15-20 dessas empresas localizadas em lugares dispersos;

b) falta de padrões na indústria para intercâmbio de informaçôes. Com o aumento do uso de computadores, cada vez mais as informaçóes geradas na construção são transmitidas em forma digital. No entanto, por causa da falta de um padrão de armazenamento de informação e de comunicação, a 
troca de informações eletrônica entre os programas, tarefas e empreendimentos ainda é pouco comum;

c) comunicação interdisciplinar ineficiente. Um projeto de construção típico envolve várias "disciplinas" - arquitetos, engenheiros de estrutura, técnicos em serviços de edificações, empreiteiros, fornecedores de materiais, etc. - colaborando por períodos relativamente curtos no design e na construção propriamente dita de uma instalação. Até recentemente, essas disciplinas tendiam a trabalhar independentemente, tomando decisões que afetavam umas as outras. A pobre comunicação interdisciplinar durante o projeto é considerada como um "gargalo" para o melhoramento da performance, e reforça o confronto cultural tão comum na indústria da construção;

d) administração deficiente do conhecimento, no nivel da indústria, do empreendimento e do projeto. A construção é um projeto baseado no processo. Muitas vezes, existe uma crença de que cada projeto é único, sendo que o conhecimento adquirido em um projeto não poderá ser utilizado em outros. No entanto, estudos mostram que o processo de construção em si repete-se em sua essência de projeto para projeto (Egan, 1998). Um melhor gerenciamento do conhecimento iria permitir capturar e reutilizar desse conhecimento tanto no projeto quanto no empreendimento e na indústria como um todo.

Sem dúvida, grande parte da solução para os problemas acima relacionados está na integração dos processos, incluindo a cadeia de suprimentos da construção. Os benefícios potenciais através da integração na construção incluem redução de custos, eliminação de processos desnecessários, promoção de cultura de parceria e trabalho em equipe, aumento da satisfação do cliente, etc.

Os recentes avanços nas TIs, especialmente nos softwares SGI, oferecem uma plataforma para o desenvolvimento dessas soluçôes integradas. O objetivo da integração é proporcionar um gerenciamento coerente e o compartilhamento de informações e conhecimento durante os projetos de construção. Em outras palavras, a integração dos processos de construção requer um sistema integrado de TIs que habilitará os membros da equipe de projetos a trabalharem juntos compartilhando as informações sobre o projeto. 
Essa integração ajudaria a atingir um dos objetivos mais importantes para o aumento da produtividade na indústria da construção, que é a redução do longo ciclo de rotação do capital, devido à extensão do ciclo produtivo.

Há, também, uma outra faceta a ser considerada em relação às dificuldades de integração no setor da construção, que é o fato de que projetos de construção - sejam edifícios, pontes, barragens, etc. - normalmente envolverem muitos estágios (com suas subjacentes atividades e tarefas), começando das exigências do cliente e passando pelo design, construção, utilização e eventual venda de uma obra. Esses estágios do ciclo de vida do projeto, mais as atividades e tarefas a eles associadas, são freqüentemente empreendidos como processos separados, com uma integração apenas limitada de dados/informações dos participantes, das ferramentas, dos procedimentos, etc.

Ou seja, a falta de coordenação e de uma abordagem estratégica entre as etapas do ciclo de vida do projeto, e que suscitam o desenvolvimento de sistemas integrados, resultam nas chamadas "ilhas de automação", quais sejam: a arquitetura, a engenharia e a construção. ${ }^{8}$ A importância de construir "pontes" entre estas várias "ilhas de automação" agora é reconhecida e vem assumindo grande importância no setor e, por conseqüência, afeta as empresas que desenvolvem software para este nicho.

Nesse sentido, houve vários esforços de integração ao longo dos anos que, no início, eram focados na integração entre os sistemas CAD - ComputerAided Design com uma variedade de outras aplicações. Esses primeiros sistemas $\mathrm{CAD}$ eram prejudicados, em sua funcionalidade e eficiência, devido às limitaçôes na estruturação dos dados, na memória, no poder de processamento, no desenho da interface e aos seus altos custos, entre outros fatores.

Mais recentemente, novas tentativas de integração foram facilitadas por numerosos avanços tecnológicos, tais como: hardware mais rápido e poderoso, aumento na capacidade de memória e redução de seu custo, processamento paralelo e distribuído, maior flexibilidade na estruturação dos dados e no design do software, sistemas baseados no conhecimento, conceitos de programação orientada a objetos e melhoramentos no desenho da interface com o usuário.

8 Obviamente, a construção não se encaixa em um conceito strictu sensu de "ilha de automação" por causa de seu caráter muitas vezes artesanal. A idéia é de "ilhas" tecnológicas dentro de um mesmo setor que funcionam de forma pouco integradas, ou ainda, isoladas. 
Algumas dessas iniciativas recentes de integração incluem: integração dos dados do produto, integração do processo, multidisciplinaridade e integração da cadeia de fornecedores, ferramentas de integração e integração intranegócios (Anumba, 1996).

Os desafios atuais de integração na indústria da construção estão principalmente centralizados na integração de produto e processo, e na integração da empresa como um todo, incluindo a cadeia de fornecedores e todas as unidades da empresa. Do lado da integração de produto e processo, a modelagem de uma solução em software integrado deveria estar apta a (Anumba et al., 1998):

- dar suporte a múltiplas tarefas;

- fornecer suporte efetivo ao longo do processo de design e construção;

- automatizar a transferência de dados entre as diferentes tarefas do sistema;

- facilitar a efetiva comunicação entre as heterogêneas ferramentas de software, de modo a proporcionar a total integração durante todo o ciclo de vida do projeto;

- fornecer um certo grau de "inteligência” em auxílio a um contexto dado.

Ainda segundo esses autores (Anumba et al., 1998), quanto à integração da empresa como um todo, o que representa uma evolução natural dos demais tópicos de integração, os desafios estariam em:

- integrar o legado de ferramentas de software que estão sendo usados pelos vários setores da cadeia de suprimentos da construção;

- o desenvolvimento de modelos apropriados de projetos que permitam a distribuição dos grupos de trabalho de forma que efetivamente "falem a mesma língua";

- desenvolver ferramentas e técnicas apropriadas para facilitar o planejamento dos recursos da empresa ERP e do custo total;

- garantir a segurança da transferência de informações por meio digital entre as várias seções e unidades da empresa.

Apesar de todas as virtudes, possibilidades e desafios acerca das TIs, destacadas anteriormente, a indústria da construção ainda se caracteriza pelo baixo 
grau de utilização dessas ferramentas, principalmente em países em desenvolvimento como o Brasil. Nas empresas construtoras, principalmente nas médias e pequenas, as TIs são basicamente aplicadas em programas contábeis e administrativos, programas de cálculo e simulações, sistemas de orçamentos, planejamento e controle de obras, sistemas CAD e, ultimamente, está se generalizando nelas o uso da Internet e do correio eletrônico.

O uso das TIs em setores tradicionalmente pouco inovativos como é o da construção, mesmo que ainda de forma tímida em países em desenvolvimento, vêm se acelerando. O que está acontecendo no setor, no entanto, é que grande parte das empresas está introduzindo as TIs inicialmente como meio de automatizar suas tarefas. A disseminação das TIs em seus processos dependerá, então, da capacidade das empresas em visualizarem as TIs como criadoras de benefícios sistêmicos (modificadoras de processos, com aumento da eficácia) e também da capacidade das empresas para realizar os investimentos necessários para que isso aconteça.

Pode-se afirmar, portanto, que existe uma crescente demanda por soluçōes integradas por computador na construção, sendo o setor um exemplo de um nicho onde as software-houses brasileiras podem atuar. No entanto, para isso elas devem conhecer as características dessa indústria altamente fragmentada, o que implica grandes desafios na integração de seus processos dentro da empresa usuária como um todo.

A indústria da construção tem várias necessidades específicas que devem ser levadas em consideração pela comunidade desenvolvedora de softwares de gestão integrada, mais especificamente os de sistemas ERP. Por ser uma indústria fragmentada com segmentos específicos, requer sistemas especializados e integrados.

Com a finalidade de identificar a atuação das empresas de software dentro da indústria da construção mais detidamente, foi realizada uma pesquisa de campo dentro de um projeto da FAPESP, ${ }^{9}$ através de questionários aplicados a 190 empresas do painel retirado do Cadastro do SindusCon contendo algumas questôes, divididas em três partes:

\footnotetext{
9 Para esta análise os autores valeram-se de uma abordagem geral da informatização na indústria da construção através de tabulações da PAEP, incluídas em uma publicação da revista do SindusCon - Sindicato da Construção Civil (Brisolla et al., 2001) e da participação em um projeto financiado pela Fundação de Amparo à Pesquisa no Estado de São Paulo (FAPESP), finalizado em maio de 2001, sobre a própria indústria da construção: "A Constituição de Blocos Econômicos como Resposta à Globalização: os Efeitos do Mercosul sobre a Indústria da Construção em São Paulo" - coordenadoras: Profa ${ }^{a}$. Dra. Sandra de Negraes Brisolla (UNICAMP-IG/DPCT) e Prof ${ }^{a}$. Dra. Délia Beatriz Espina (PUCCAMP - Fac. Ciências Econômicas, Contábeis e Administrativas).
} 
TABELA 3

Empresas que utilizam Software de Gestão Integrada

\begin{tabular}{lccccc}
\hline Softwares Integrados & \multicolumn{5}{c}{ Faixa de P. O. (Pessoal Ocupado) } \\
\hline & $<20$ & 20 a 99 & 100 a 499 & $>500$ & Total \\
SAP & 2 & 0 & 1 & 4 & 7 \\
Oracle & 0 & 0 & 0 & 3 & 3 \\
Total & 2 & 0 & 1 & 7 & 10 \\
Total percentual (\%)* & 11,76 & 0,00 & 3,33 & 63,64 & 10,31 \\
Seis mais citados (nacionais) & & & & & \\
RM & 0 & 2 & 7 & 0 & 9 \\
SIECON & 6 & 2 & 0 & 0 & 8 \\
SIENGE & 0 & 2 & 4 & 0 & 6 \\
SISCORP & 0 & 1 & 4 & 0 & 5 \\
Microsiga & 0 & 0 & 3 & 2 & 5 \\
STRATO & 0 & 4 & 1 & 0 & 5 \\
Total & 6 & 11 & 19 & 2 & 38 \\
Total percentual (\%)* & 35,29 & 28,21 & 63,33 & 18,18 & 39,18 \\
Outros softwares citados & 3 & 15 & 7 & 4 & 29 \\
Total geral & 11 & 26 & 27 & 13 & 77 \\
Total no de empresas** & 20 & 54 & 37 & 15 & 126 \\
Total percentual (\%) & 55,00 & 48,15 & 72,97 & 86,67 & 61,11
\end{tabular}

Fonte: elaboração própria a partir dos dados colhidos na Pesquisa FAPESP/Sinduscon, 2001.

* em relação ao número total de empresas por faixa de P.O. subtraindo-se os "outros softwares citados."

** Obs.: do painel de 190 empresas, apenas 126 responderam as questões relativas ao software.

i) quanto à utilização dos softwares integrados de gestão empresarial, conhecidos como ERP;

ii) quanto ao uso de softwares específicos para a construção, vendidos sob a forma de pacotes;

iii) quanto à aquisição de softwares sob encomenda, seja administrativos ou produtivos.

Foram feitas ainda indagações quanto ao impacto desses softwares sobre as empresas, tanto do ponto de vista de um maior domínio tecnológico, quanto da elevação de sua produtividade. 
De acordo com os critérios discutidos anteriormente, o foco nesta breve descrição dos dados colhidos na pesquisa será sobre os softwares integrados, já que se trata de uma necessidade premente na indústria da construção e um exemplo de campo de atuação para as softwares-houses brasileiras em nichos específicos, sendo essa uma indústria tipicamente nacional, o que facilita as interações usuário-produtor na confecção destes tipos de software, possibilitando adaptações às necessidades locais.

Os resultados da pesquisa de campo quanto ao uso de softwares integrados na construção foram buscados dando destaque aos sistemas ERPs da SAP (R/3) e da Oracle (Oracle Applications). Além destes, mais complexos, selecionaram-se os seis mais citados na resposta ao questionário (Tabela 3 ).

Pode-se perceber que existe um alto percentual de utilização de softwares de gestão integrada na indústria da construção, atingindo $61 \%$ do total das empresas que responderam ao questionário. Como já era de se esperar, os SGIs são mais comuns nas empresas que possuem maior número de funcionários ( $73 \%$ na faixa de P.O. entre 100 a 499 e quase $87 \%$ na faixa acima de 500 empregados). ${ }^{10}$

É interessante notar que desses seis softwares mais utilizados, e que são de empresas nacionais, três deles foram desenvolvidos para as especificidades da indústria da construção: SINGE - Sistema Integrado de Engenharia, STRATO (ERP para Construtoras e Incorporadoras) e SIECON - Sistema Integrado Especializado em Construção. Devido ao percentual de utilização maior destes seis softwares mais citados principalmente nas empresas que se encontram na faixa de P.O. entre 100 a 499 (em torno de 63,33\%) em relação aos dois primeiros, os softwares SAP e Oracle (3,33\% somam SAP e Oracle para esta faixa), é razoável aceitar a hipótese de que o custo de SGIs (segmento midrange) já passa a ser mais acessível às empresas de médio porte, tornando sua utilização mais habitual.

Por outro lado, a pesquisa confirma o caráter hierarquizado na divisão do trabalho da indústria de software, ou seja, o segmento de maior lucratividade (high-end) fica a cargo das gigantes internacionais, como a alemã SAP e a estadunidense Oracle $(68,64 \%$ na faixa acima de 500 empregados para a soma destas últimas contra $18,18 \%$ das nacionais para a mesma faixa), enquanto no segmento médio (midrange) a participação das softwares-houses nacionais é maior, conforme já assinalado.

\footnotetext{
10 Os dados referentes à faixa de P. O. "<20" (de menos de 20) empregados podem estar um pouco superestimado, devido a um número considerável de questionários não respondidos estar concentrado nesta faixa.
} 
Claro que, também, visto por outro prisma, isso pode indicar oportunidades de participação em um segmento que é basicamente nacional, através do aproveitamento das especificidades locais, o que seria uma janela de oportunidade a ser aproveitada pelas empresas do setor de software. Isso foi detectado em relação às questões sobre softwares específicos usados na construção, o que não é tratado aqui em profundidade. Por exemplo, o software Volare, o mais citado e possivelmente um dos mais usados na indústria da construção, tem como finalidade gerenciar obras, integrando orçamento, planejamento, controle e fiscalização. Ele resume o que se pode observar quando se pensa na necessidade crescente de redução de custos neste setor e é adaptado às características nacionais. Essa adaptação devese em parte ao aprendizado acumulado pela empresa que desenvolveu esse software, a PINI Sistemas. Na verdade, a PINI Sistemas surgiu das expectativas detectadas pela Editora PINI, empresa fundada em 1948, que produz informações setoriais no Brasil e está orientada para a prestação de serviço a empresas de projetos, construtoras de edificações, empreiteiras de obras públicas e montagens industriais. Através do profundo conhecimento relativo ao setor e devido a suas características tipicamente nacionais, passou também a atuar no mercado de software.

$\mathrm{O}$ caso da PINI Sistemas também traz à tona outra característica da indústria de software, a convivência entre fragmentação e concentração. $\mathrm{Ou}$ seja, abre-se a oportunidade, por um lado, de atuação em uma indústria como a da construção e, por outro lado, inicia-se um processo de concentração, com poucas empresas abocanhando maiores fatias de mercado. É o caso da PINI Sistemas, mesmo que em proporção bem menor em relação a outros segmentos. Vários softwares que foram citados na pesquisa são desenvolvidos por esta empresa, tais como o ERP STRATO (em parceria no desenvolvimento com uma empresa de Florianópolis), o Volare, o ArCon (parceria, também, com uma empresa alemã), entre outros.

Além disso, ainda em relação à hierarquização e concentração, percebe-se que muitos softwares como o TRON-ORC (produto específico também bastante utilizado), da Tron Informática, que auxiliam no orçamento e planejamento da obra, têm que se moldar aos padrões estabelecidos, interagindo com programas como o MS Project da Microsoft. Claro que não se pretende sugerir ou incentivar a prática de "reinventar a roda"; trata-se apenas de destacar uma das características do setor de software. 
TABELA 4

Impactos do software de gestão após sua implementação

\begin{tabular}{lll}
\hline Variável & Freq. Sim $\quad N^{\circ}$ respostas $\quad \% \mathrm{~F} / \mathrm{N} \quad$ Intervalo de $95 \%$ de confiança
\end{tabular}

Maior domínio

tecnológico

Melhoria da produtividade

de trabalho

Melhoria da produtividade global
73

72

79

82

$89,02 \%$

$91,14 \%$

$82,59 \%$

$96,36 \%$

82

$71,95 \%$

$60,94 \%$

$81,32 \%$

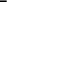

Fonte: elaboração própria a partir dos dados colhidos na Pesquisa FAPESP/Sinduscon, 2001.

Em relação aos softwares de gestão integrada, percebeu-se, através das respostas obtidas, que, ao que tudo indica, esses softwares vêm contribuindo tanto para um maior domínio tecnológico quanto para a melhoria da produtividade das empresas da construção (Tabela 4).

No entanto, segundo dados colhidos em entrevistas diretas, ${ }^{11}$ ainda há carência de pacotes ERP verdadeiramente integrados para a construção. Pacotes que são fortes em gerenciamento de projetos podem ser fracos em programação e estimativas da produção e vice-versa. Em muitos casos, as empresas da construção têm que adquirir o melhor que os vendedores podem oferecer e combinar com produtos adquiridos de terceiros, a fim de desenvolver sistemas específicos para a construção, ou ainda, com desenvolvimento interno.

Além disso, não bastassem os custos de implantação e o dispêndio de tempo para tal, existem ainda custos e tempo adicionais para alguma (ou muita) customização visando integrar os novos sistemas aos antigos. Muitas vezes esses custos e tempo adicionais provêm da necessidade de reprogramação de alguns dos novos módulos. Em outros casos, os velhos sistemas exigirão

\footnotetext{
${ }^{11}$ Esses dados qualitativos são resultado de entrevistas realizadas com empresas da indústria da construção no Estado de São Paulo, de maneira complementar ao trabalho de pesquisa financiado pela FAPESP, já mencionado.
} 
mudanças significativas, seja para continuar em operação conjunta ou para o processo de migração.

Nos últimos anos, a questão de implantar ou não um sistema ERP tinha sido considerada importante. Hoje ficou claro que, para continuarem bemsucedidas, as companhias terão que implementar de alguma forma sistemas integrados de gestão, como o ERP, o que é válido e já palpável principalmente para empresas de grande porte da construção, e mais ainda para firmas brasileiras.

Não existe ainda um padrão ou uma "melhor" metodologia para a implementação de sistemas ERP. Cabe às empresas, tanto da construção como as produtoras de software integrado, dentro da relação usuário-produtor, introduzir o software ERP da melhor maneira, de forma a se adequar às suas necessidades de operação. Embora muitas empresas estejam, de modo geral, satisfeitas com o desempenho de seus sistemas ERP, elas gostariam de ver esforços mais concentrados por parte dos produtores dessas tecnologias em atender às especificidades inerentes ao processo produtivo da indústria da construção. Outro problema relacionado a esse é que os sistemas integrados existentes são feitos sob medida, normalmente são demasiado caros, excessivamente lentos na implementação, requerem alguma infra-estrutura de suporte e muitas vezes ultrapassam a capacidade das empresas.

Sendo assim, esses tipos de preocupações e análises devem ser levados em consideração pelas empresas que desenvolvem softwares do segmento vertical, tanto na elaboração de softwares-pacotes como dos customizados. Como existem essas características específicas da indústria da construção, certamente existirão outras nas demais indústrias ou "nichos" que devem ser explorados. E, sendo bem exploradas, possibilitam a aquisição de conhecimento, aprendizado e construção de competências para elevar sua participação no mercado, nacional e internacional, de forma mais qualificada.

\section{Conclusão}

Nessa nova organização da sociedade ou, em outras palavras, nesse novo tipo de sistema que alguns autores, como Castells (1999), vêm chamando de "capitalismo informacional" e que está intimamente associado ao desenvolvimento do novo paradigma técnico-econômico - tendo o extraordinário desen- 
volvimento da microeletrônica como um dos elementos-chave - destaca-se a acelerada difusão das novas TIs. Estas possibilitam radical ruptura quanto à extensão dos contatos e de trocas de informaçōes possíveis entre os atores, individuais e coletivos, mediante a diferenciação e ampliação de sistemas, canais, redes e organizações de geração, tratamento e difusão de informações. É o que se convencionou denominar "revolução informacional". O conhecimento passa a ser a base do sistema, a ter valor mercadológico cada vez mais decisivo. As TIs, por sua vez, sustentam o desenvolvimento da capacidade de gerenciamento de negócios, cada vez mais magnificados e internacionalizados, através de tecnologias de informática. Estas possibilitam o processamento de grande quantidade de dados e informações, a constituição e o gerenciamento de bancos de dados integrados e a implantação de redes de comunicação, que constituem o que se denomina "sistemas integrados de gestão empresarial" (Freire \& Brisolla, 2001).

Assim, os impactos sobre a competitividade derivados da difusão de tecnologias da informação e comunicação têm diferentes aspectos. Por um lado, a empresa tem incertezas estáticas e dinâmicas no processo de escolha tecnológica, e desenvolve funções para lidar com estas incertezas. Como a redução das incertezas impulsiona o processo inovador e conseqüentemente a competitividade das firmas, o impacto positivo da difusão de tecnologias da informação sobre a competitividade é evidente, uma vez que estas permitem administrar as incertezas de modo mais eficiente. Por outro lado, a adoção de TIs também pode proporcionar às empresas uma significativa redução de custos, ao permitir que as empresas acessem clientes, fornecedores e estoques eletronicamente.

Neste contexto, o software passa a ser um dos elos de ligação na corrente das mudanças estruturais, fazendo com que sua análise seja importante em estudos e políticas setoriais. O software é, então, um elemento intrínseco e de atuação intensa dentro do paradigma das TIs, pois, por um lado, possui as características básicas necessárias para a implementação de sistemas baseados na microeletrônica, e por outro lado é uma tecnologia "descorporificada", ou seja, seu produto é intangível, mas tem seu valor determinado pelo quão efetivas são as operações computacionais realizadas, bem como por quão confiáveis são os resultados obtidos.

A inserção do software em um setor tradicional, como o da construção, demonstra que as TIs vêm se difundindo amplamente, servindo não só de apoio 
administrativo mas também como ferramenta estratégica nas empresas do setor, pois, nas atuais circunstâncias, um orçamento/planejamento de obras ou um cálculo estrutural mais bem elaborado, por exemplo, podem vir a fazer toda a diferença na disputa de mercados competitivos como o dessa indústria.

Esse estudo possibilitou, também, exemplificar alguns traços característicos da indústria de software que estão presentes mesmo em uma indústria peculiar como a construção. O caráter "transversal" do software, por exemplo, cada vez mais toma corpo nesta indústria, por força da premente necessidade de construir "pontes" para interligar as chamadas "ilhas de automação da construção" (arquitetura, engenharia e construção). Assim, o software passa por todo o processo interligando os diferentes segmentos e configurando-se, também, como parte integrante do todo, além de contribuir de forma decisiva para diminuir o longo tempo de rotação do capital, reduzindo a extensão do ciclo produtivo na construção, multiplicando o volume de produção por unidade de tempo.

A introdução progressiva do software na indústria da construção, mesmo se tratando de uma indústria com processo "artesanal", exemplifica, em primeiro lugar, a característica de estratégia de nicho e, em segundo, a importância do investimento na indústria de software para alavancar a competitividade em outras áreas da economia.

$\mathrm{Na}$ outra ponta estratégica, para o Brasil, a internacionalização de sua indústria de software, que poderia ser considerada precoce ou mesmo prematura, se comparada aos outros setores da atividade econômica, além de uma necessidade, é uma exigência para se conseguir inclusive competitividade interna, aproveitando as capacidades locais em muitos segmentos e nichos específicos.

Com essa estratégia de sobrevivência pode-se, de qualquer forma, conseguir um desenvolvimento significativo nos casos em que as empresas nacionais de software procuram agregar valor aos serviços prestados nas parcerias, incorporando produtos desenvolvidos localmente aos comercializados pelas empresas estrangeiras.

Sem dúvida, há muito o que fazer ainda para a melhoria da qualidade nas empresas brasileiras de software, visando cultivar e ampliar suas vantagens competitivas. A expansão do mercado conquistada nos últimos anos faz com que empresas estrangeiras se interessem em realizar grandes investimentos no País. Em contrapartida, cabem ações governamentais que visem promover as empre- 
sas nacionais, estimulando-as não só a competir pelo mercado interno como, também, a buscar novos mercados no exterior.

Obviamente, a ampla possibilidade de aplicação do software não apenas abrange as indústrias tradicionais, como o caso limite aqui analisado, de uma indústria quase artesanal, como a da construção, porém, muitas vezes, é justamente nestas que ela possibilita maior salto de produtividade, exatamente porque parte de um patamar mais baixo de organização industrial.

É, portanto, o caráter transversal do software e sua aplicação quase universal que potencializa o efeito multiplicador do investimento no setor. Sua difusão pela economia é uma reação em cadeia em toda a extensão dos mais diversos setores de atividade, reduzindo o diferencial de lucratividade entre eles e ampliando seu grau de integração.

Tendo como referência teórica os sistemas nacionais de inovação, a política científica e tecnológica brasileira está se propondo a estimular a criação de redes setoriais ou locais de inovação, com o objetivo de constituir sistemas integrados reunindo instituições vinculadas ao estudo de tecnologias relacionadas a determinadas cadeias produtivas e setores de atividade. Essas instituiçôes incluem laboratórios de pesquisa governamentais ou privados cujas atividades teriam que ser integradas às iniciativas de inovação por parte de setores industriais, através da realização de projetos conjuntos de $\mathrm{P} \& \mathrm{D}$, bem como de iniciativas no sentido da transferência de tecnologia para as empresas.

Um primeiro desafio consiste na articulação de políticas públicas diversas para setores correlacionados. Assim, as políticas dirigidas para a área de software, ainda que tenham sua especificidade, relacionam-se de perto com aquelas voltadas para as áreas de semicondutores e de telecomunicações.

Entre os instrumentos de política voltados para o preenchimento das inúmeras lacunas existentes nessas redes no País, destacam-se algumas iniciativas de legislação promotora de inovações, como o Decreto 4.928, de dezembro de 2003, que permite a dedução de despesas operacionais com atividades de inovação no cálculo da Contribuição Social sobre o Lucro Líquido, além de permitir que se deduza o total do valor utilizado para o desenvolvimento de um produto ou processo que tenha conduzido ao registro de uma patente no INPI, também para o mesmo tributo (TI \& Governo).

Estão previstas a partir de agosto de 2004 a aprovação da Lei de Inovação, 
que deve ser seguida pela criação da Agência Brasileira de Desenvolvimento Industrial e a renovação da Lei de Informática.* O Ministério da Ciência e Tecnologia - MCT prepara um projeto de lei para enviar ao Congresso Nacional criando uma política deincentivos fiscais para as empresas que investirem em inovação tecnológica, cuja novidade consiste na utilização do poder de compra do Estado para as empresas.

Uma das medidas da política será a implantação do Lattes tecnológico uma plataforma do Conselho Nacional de Desenvolvimento Científico e Tecnológico (CNPq) que inclui currículos dos pesquisadores e a relação dos institutos de pesquisa. A idéia é que o Lattes sirva de ligação entre pesquisadores, institutos e o setor produtivo. Segundo entrevista do ministro Eduardo Campos ao semanário TI \& Governo, "será um grande portal de encontro da expertise tecnológica dos diversos centros e grupos de pesquisa, e até de pesquisadores individualmente, e a demanda". Segundo o ministro, as demandas das empresas serão mantidas em sigilo para evitar problemas com a concorrência. "Instrumentos como esse vêm na seqüência da Lei de Inovação.”

O Ministério do Planejamento, Orçamento e Gestão - MP espera concluir em breve a etapa de elaboração de projetos de modernização das administrações estaduais no âmbito do PNAGE, um programa que prevê investimentos de US $\$ 310$ milhões em TIs e matrizes teóricas (desenho de modelos de logística de compra, fluxos de processos).

A Lei de Inovação vai levar à alteração na Lei de Licitações, a 8.666, para incluir um dispositivo que dá preferência nas compras governamentais às empresas que investem em inovação. A intenção é que a Lei de Inovação permita levar a pesquisa da universidade para as empresas.

$\mathrm{Na}$ discussão das políticas voltadas para áreas prioritárias, o software ocupa um lugar estratégico, na medida em que afeta a quase totalidade dos setores industriais que se estão modernizando. A prática recente do MCT de organizar a elaboração, execução e controle das políticas através de reuniões setoriais da comunidade científica, e a participação de setores industriais, pode dar muitos frutos na conformação do desejável sistema setorial de inovação, não apenas no caso do software.

\footnotetext{
* N.E.: a Lei de Inovação (Lei n 10.973) foi promulgada em 2/12/2004 e a ABDI foi criada em 30/12/2004 através da Lei $n^{\circ} 11.080$, regulamentada pelo Decreto 5.352 de 24/1/2005.
} 


\section{Referências bibliográficas}

Anumba, C.J., "Functional Integration in CAD Systems, Advances", in Engineering Software, 25(2/3), p.103-109, 1996.

Anumba, C.J.; Cutting-Decelle, A.F; Baldwin, A.N.; Dufau, J.; Mommessin, M.; Bouchlaghem, N.M., "Integration of Product and Process Models as a Keystone of Concurrent Engineering in Construction: the ProMICE Project", in Amor, R. (org.), Proceedings 2nd European Conference on Product and Process Modelling, 19-21, out., p.9-20, 1998.

100 Maiores Integradores 2004, Os, São Paulo: IDG-Brasil, 2004.

Bazjanac, V., "The promises and the disappointments of Computer Aided Design”, in Negroponte, N. (org.), Computer Aids to Design and Architecture, Londres: Mason/Charter, 1975.

Brisolla, S.; Espina, D.; Massei, W.; Freire, E., "A Indústria da Construção em São Paulo face ao Processo de Globalização e Regionalização da Economia", in Revista Estudos Econômicos da Construção, v.5, n.1 (8), p.35-87, São Paulo: SindusCon (Sindicato da Indústria da Construção), 1999.

Cassiolato, J.E., "The user-producer connection in high-tech: a case-study of banking automation in Brazil", in Schmitz, H.; Cassiolato, J., High-tech for Industrial Development, Londres: Toutledge, 1992.

Cassiolato, J.E.; Lastres, H.M.M., "Inovação, globalização e as novas políticas de desenvolvimento industrial e tecnológico", in Cassiolato, J.E.; Lastres, H.M.M., Globalização e Inovação Localizada - Experiências de Sistemas Locais no Mercosul, Brasília: MCT, OEA e Instituto Euvaldo Lodi (IEL) da Confederação Nacional da Indústria, 1999.

Castells, M., A Sociedade em Rede, São Paulo: Paz e Terra, 1999.

D’Adderio, L., “The Diffusion of Integrated Software Solutions: Trends and Challenges", texto para discussão, in ESSY - Sectorial Systems in Europe Innovation, Competitiveness and Growth, SPRU, 2000.

Davenport, T., "Putting the Enterprise into the Enterprise System", in Harvard Business Review, jul/ago, Boston, 1998.

Edquist, C. (org.), Systems of innovation, Londres: Frances Pinter, 1997.

Egan, J., Rethinking Construction, Department of Environment, Transport and Regions (DETR), UK, 1998.

Freire, E.; Brisolla, S. N., "Innovation and Competitiveness: The challenge to be faced by the Brazilian Software Industry", artigo apresentado in ECIS Conference on the 'Future of Innovation Studies', Eindhoven, Netherlands, 2001. 
Grimaldi, R ; Torrisi, S., "Codified-Tacit and General-Specific knowledge in the division of labour among firms. A study of the Software Industry", in Liuc Papers n.85 - Serie Economia e Impresa, abr., 2001.

López, A.; Lugones, G., "Los sistemas locales en el escenario de la globalización", in Cassiolato, J.E.; Lastres, H.M.M. (orgs.), Globalização e Inovação Localizada - Experiências de Sistemas Locais no Mercosul, Brasília: MCT, OEA e Instituto Euvaldo Lodi (IEL) da Confederação Nacional da Indústria, 1999.

Lundvall, B. (org.), National systems of innovation. Towards a theory of innovation and interactive learning, Londres: Pinter, 1992.

Malerba, F.; Torrisi, S., "The Dynamics of Mark Structure and Innovation in Western European Software Industry", in The International Computer Software Industry - A Comparative Study of Industry Evolution and Structure, Oxford: Oxford University Press, 1996.

Malerba, F., Sectoral Systems of Innovation and Production, Milão, CESPRI, 1999. , "Sectoral Systems of Innovation and Production: Concepts, Analytical Framework and Empirical Evidence", artigo apresentado in Ecis Conference "The Future of Innovation Studies", Eindhoven - Netherlands, set., 2001.

Nelson, R., National Innovation Systems: a comparative study, Oxford: Oxford University Press, 1993.

Smith, K., "Systems Approaches to Innovation: some policy issues", texto para discussão do projeto de pesquisa in Innovation Systems and European Integration - ISE, STEP Group, Oslo, 1997.

Sutz, J., "Estudios Sociales de la Ciencia y de la Tecnologia en America Latina: ¿en busca de una agenda?", in Albornoz, M.; Kreimer, P.; Glavich, E. (orgs.), Ciencia y sociedad en America Latina, Colección Ciencia, Tecnologia y Sociedad, Buenos Aires: Universidad de Quilmes, 1996.

, "La caracterización del Sistema Nacional de Innovación en el Uruguay: enfoques constructivos", in Cassiolato, J.E.; Lastres, H.M.M. (orgs.), Globalização e Inovação Localizada - Experiências de Sistemas Locais no Mercosul, Brasília: MCT, OEA e Instituto Euvaldo Lodi (IEL) da Confederação Nacional da Indústria, 1999.

Steinmueller, W. E., The European Software Sectorial System of Innovation, mimeo, 2001.

TI \& Governo, Plano Editorial, http://www.planoeditorial.com.br. 